\title{
Effect of Multisensory Stimulation on Analgesia in Term Neonates: A Randomized Controlled Trial
}

\author{
CARLO VALERIO BELLIENI, FRANCO BAGNOLI, SERAFINA PERRONE, ANNA NENCI, \\ DUCCIO MARIA CORDELLI, MARA FUSI, \\ SIMONA CECCARELLI, AND GIUSEPPE BUONOCORE
}

Department of Pediatrics, Obstetrics, and Reproductive Medicine, University of Siena, Italy

\begin{abstract}
ABS
Many attempts have been made to obtain safe and effective
analgesia in newborns. Oral glucose-water has been found to
have analgesic properties in neonates. We investigated whether
other sensory stimulation added to oral glucose provided more
effective analgesia than oral glucose alone. In a randomized
prospective double-blind trial, we studied 120 term newborns
during heel prick. The babies were divided randomly into six
groups of 20 , and each group was treated with a different
procedure during heel prick: $A$ ) control; $B$ ) 1 mL $33 \%$ oral
glucose given 2 min before the heel prick; $C$ ) sucking; $D$ ) 1 mL
$33 \%$ oral glucose plus sucking; $E$ ) multisensory stimulation
including $1 \mathrm{~mL} 33 \%$ oral glucose (sensorial saturation); $F$ )
multisensory stimulation without oral glucose. Sensorial satura-
tion consisted in massage, voice, eye contact, and perfume
smelling during heel prick. Each heel prick was filmed and
\end{abstract}
assigned a point score according to the Douleur Aiguë du Nouveau-né (DAN) neonatal acute pain scale. Camera recording began $30 \mathrm{~s}$ before the heel prick, so it was impossible for the scorers to distinguish procedure A (control) from B (glucose given 2 min before), C (sucking water) from D (sucking glucose), and $\mathrm{E}$ (multisensory stimulation and glucose) from $\mathrm{F}$ (multisensory stimulation and water) from the video. Procedure E (multisensory stimulation and glucose) was found to be the most effective procedure, and the analgesia was even more effective than that produced by procedure D (sucking glucose). We conclude that sensorial saturation is an effective analgesic technique that potentiates the analgesic effect of oral sugar. It can be used for minor painful procedures on newborns. (Pediatr Res 51: $460-463,2002$ )
Newborns feel pain $(1,2)$. Repeated painful stimuli lower their pain threshold $(3,4)$ by overstimulation of NMDA receptors, which may lead to excitotoxic brain damage (5). Until a few years ago, it was claimed that the word pain was inappropriate for newborns, as pain is a subjective experience that newborns, because of their age, cannot have (6). Until the 1980s, analgesics were rarely administered to newborns even in the case of surgery (7). Now we know that anesthesia reduces brain damage due to hypoxemia, hypertension, tachycardia, variations in heart rate, and increased intracranial pressure $(8,9)$, all of which are particularly dangerous because of immature cerebral vasoregulation in the premature (10).

The number of painful stimuli needs to be kept to a minimum, and every effort should be made to render them less painful. Guidelines for neonatal analgesia have been suggested (11-15), especially for the most routine type of pain, blood sampling, which is usually performed by heel prick. To avoid the drawbacks of general and local analgesics (16-21), types of nonpharmacologic analgesia have been proposed, including

Received June 25, 2001; accepted August 10, 2001.

Correspondence: Giuseppe Buonocore, M.D., Department of Pediatrics, Obstetrics, and Reproductive Medicine, University of Siena, Policlinico "Le Scotte," V. le Bracci 36, 53100 Siena, Italy: e-mail: buonocore@unisi.it nonnutritional sucking and instillation of glucose or other sweet liquids on the newborn's tongue (22). The analgesic effect of glucose is thought to stimulate an increase in plasma concentrations of $\beta$-endorphin (23-27) by a preabsorptive mechanism (28).

Very recently, we observed that sensory stimuli combined with oral glucose during heel prick greatly reduced manifestations of pain in preterm babies (29). This combination was even more effective in premature babies than oral glucose. We called it sensorial saturation (SS) because it works through competition between nonpainful and painful stimuli, not to indicate that nonpainful stimuli cause saturation of sensorial pathways. In the present study, we investigate whether SS promotes analgesia in term babies and whether it is more effective than that obtained with sugar alone. We also studied the various components of SS (sucking, oral glucose, other sensory stimuli) to determine which components were the most effective.

\section{METHODS}

Subjects. This prospective randomized double-blind clinical study was designed to study the reaction of normal term neonates to pain in the Siena hospital. The study was approved 
by the local ethics committee, and the parents gave their written informed consent. Five parents refused. Inclusion criteria were the following: Apgar score at least 9 at $5 \mathrm{~min}$; gestational age 38-41 wk; more than $48 \mathrm{~h}$ after delivery; more than $2 \mathrm{~h}$ after last meal; availability of the physiotherapist and a researcher to film the heel prick. The blood sampling studied was that carried out at $96 \mathrm{~h}$ of age for phenylketonuria and hypothyroid screening. This particular sampling was chosen because it is compulsory for all babies, has a standard procedure, is always carried out $3 \mathrm{~h}$ after a meal, and is long enough after delivery to permit stabilization after cesarean section. None of the babies had ever been given analgesic or sedative drugs.

Protocol. A total of 120 babies were studied. Heel prick was carried out in a quiet room barred to other persons. Parents could be present, but they had to be silent and abstain from interfering during the preparatory phase and for $30 \mathrm{~s}$ after the heel prick. The sampling was performed by experienced nurses; they held the baby's heel in their hands before the prick to warm it; after the preparatory period, they disinfected the heel and lanced it with a sterile blood lancet, waited $2 \mathrm{~s}$, and began sampling. In all cases, the analgesic procedure was carried out by the same experienced physiotherapist (A.N.).

The babies were randomly assigned to one of six groups on the basis of a random number table. Calculation of sample size with mean and SD of 2.5 showed that to achieve $80 \%$ power and 0.02 type I error $(\alpha)$ in detecting a 2-point difference in Douleur Aiguë du Nouveau-né (DAN) scale between groups, at least 17 subjects were required in each group.

Each group underwent a different procedure for the heel prick:

A Control group. No analgesic procedure.

B Glucose before heel prick. The tip of a 1-mL syringe without needle was placed in the baby's mouth, and $1 \mathrm{~mL}$ of $33 \%$ glucose solution was instilled with gentle movements of the syringe to stimulate sucking for $30 \mathrm{~s}$; heel prick was performed $120 \mathrm{~s}$ later.

C Water during heel prick (sucking). The tip of a 1-mL syringe without needle was placed in the baby's mouth, and 1 $\mathrm{mL}$ of distilled water was instilled with gentle movements of the syringe to stimulate sucking for $30 \mathrm{~s}$ before, during, and after heel prick.

D Glucose and sucking. As for C, but the syringe contained $33 \%$ glucose solution.

E Sensorial saturation. As for D, but with a series of sensory stimuli before, during, and after the heel prick (see below).

F Sensorial saturation without sugar. As for E, but the syringe contained distilled water.

We used 33\% glucose/water solution because of its availability in our ward.

The physiotherapist did not know whether the syringe contained water or glucose solution. The baby's reaction was filmed with a SONY video camera from $30 \mathrm{~s}$ before to $30 \mathrm{~s}$ after the heel prick. The films were seen by observers who did not know the method used each time. It was impossible for them to distinguish the following pairs of groups in the films: A (control) from B (glucose given 2 min before), C (sucking water) from D (sucking glucose), and E (multisensory stimu- lation and glucose) from $\mathrm{F}$ (multisensory stimulation and water).

The observers attributed a state of alertness according to the observational rating system of Prechtl and Beintema (30), which distinguishes five types of behavioral state: 1) eyes closed, regular breathing, no movements; 2) eyes closed, irregular breathing, no movements; 3) eyes open, no gross movements; 4) eyes open, continual gross movements, no crying; 5) eyes open or closed, fussing, or crying. They then assigned a score on the DAN scale (Table 1) $(31,32)$. This scale scores pain from 0 to 10 , where 0 is no pain and 10 is maximal pain. It evaluates three items: facial expression, limb movements, and vocal expression.

SS. This procedure consisted of the following: 1) laying the infant on its side with legs and arms flexed but free to move; 2) looking the infant in the face, close up, to attract its attention and, simultaneously, 3) massaging the infant's face and back; 4) speaking to the infant gently, but firmly; 5) letting the infant smell the fragrance of baby perfume (Colonia AnalcolicaHumana) on the physiotherapist's hands; 6) instilling 33\% glucose on the infant's tongue with the timing and method described in C.

Statistical analysis was performed with GBStat v 6.5 PC software, using multiple $t$ test comparisons with Bonferroni adjustment to $\alpha$ (cry data) and the Kruskal-Wallis ANOVA test for comparison of median DAN scores between groups.

\section{RESULTS}

From February to June 2001, we studied 120 newborns, all of white Caucasian race. (Table 2 shows the characteristics of the six groups of infants enrolled in the study.

Figure 1 shows mean DAN scores obtained with the five analgesic procedures and controls. We observed no statistically

Table 1. DAN*: behavioral acute pain-rating scale for neonates

\begin{tabular}{lc}
\multicolumn{1}{c}{ Measure } & Score \\
\hline $\begin{array}{l}\text { Facial expressions } \\
\text { Calm }\end{array}$ & 0 \\
$\begin{array}{l}\text { Snivels and alternates gentle eye opening and closing } \\
\text { Determine intensity of one or more of eye squeeze, } \\
\text { brow bulge, nasolabial furrow }\end{array}$ & 1 \\
Mild, intermittent with return to calm & \\
Moderate & 2 \\
Very pronounced, continuous & 3 \\
Limb movements & 4 \\
Calm or gentle movements & \\
Determine intensity of one or more of the following \\
$\quad \begin{array}{l}\text { signs: pedals, toes spread, legs tensed and pulled } \\
\text { up, agitation of arms, withdrawal reaction }\end{array}$ \\
$\begin{array}{l}\text { Mild, intermittent with return to calm } \\
\text { Moderate } \\
\text { Very pronounced, continuous }\end{array}$ \\
$\begin{array}{l}\text { Vocal expression } \\
\text { No complaints } \\
\text { Moans briefly; for intubated child, looks anxious or } \\
\text { uneasy }\end{array}$
\end{tabular}

* See Ref. 31. 
Table 2.

\begin{tabular}{|c|c|c|c|c|c|c|}
\hline & A Control & $\begin{array}{l}\text { B Glucose } \\
\text { before heel } \\
\text { prick }\end{array}$ & $\begin{array}{c}\text { C Sucking } \\
\text { water during } \\
\text { heel prick }\end{array}$ & $\begin{array}{c}\text { D Sucking } \\
\text { glucose during } \\
\text { heel prick }\end{array}$ & E SS & F SS \\
\hline Mean birth weight (range) grams & $\begin{array}{c}3320 \\
(3900-2950)\end{array}$ & $\begin{array}{c}3160 \\
(3790-2820)\end{array}$ & $\begin{array}{c}3150 \\
(3570-2840)\end{array}$ & $\begin{array}{c}3570 \\
(3900-3120)\end{array}$ & $\begin{array}{c}3610 \\
(3840-3470)\end{array}$ & $\begin{array}{c}3430 \\
(3900-2690)\end{array}$ \\
\hline Boys/girls & $11 / 9$ & $12 / 8$ & $9 / 11$ & $10 / 10$ & $9 / 11$ & $11 / 9$ \\
\hline Median arousal state score $(1-5)$ & 3 & 3 & 3 & 3 & 3 & 4 \\
\hline Range & $1-4$ & $1-4$ & $1-4$ & $1-4$ & $1-4$ & $2-5$ \\
\hline
\end{tabular}

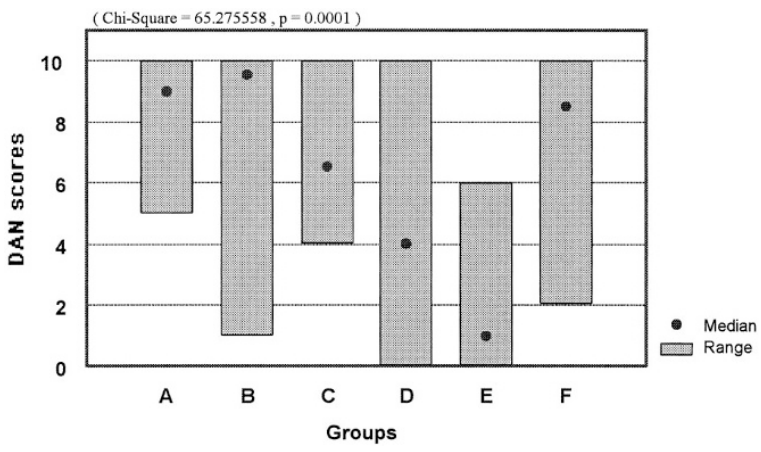

Figure 1. Comparison of median DAN scores of the five analgesic treatments and controls. $(A)$ controls, $(B)$ oral 33\% glucose, $(C)$ sucking, $(D)$ glucose and sucking, $(E)$ SS with glucose, $(F)$ sensorial stimulation without oral glucose.

significant reduction of score in procedures $\mathrm{B}$ (glucose) and $\mathrm{F}$ (SS without sugar) with respect to A (controls). Procedure C (sucking) disclosed a reduction of DAN score $(p=0.001)$, but the maximum of analgesia with respect to controls was obtained with procedures $\mathrm{D}$ (glucose plus sucking) $(p<0.0001)$ and E (SS) $(p<0.0001)$. Procedure $\mathrm{E}$ was even more effective than procedure $\mathrm{D}(p=0.004)$.

Figure 2 shows the mean duration of crying in the first $30 \mathrm{~s}$ after lancing. We observed a decrease from a mean value of $25 \mathrm{~s}$ with procedure $\mathrm{A}$ (control) to $7 \mathrm{~s}$ with procedure $\mathrm{D}$ and $2.8 \mathrm{~s}$ with procedure $\mathrm{E}$ (SS).

\section{DISCUSSION}

The methods used in previous studies of nonpharmacologic analgesia in neonates have led to a considerable reduction but not elimination of signs of pain perception $(21,33-39)$. The best results have been obtained with simultaneous administration of oral sugar and pacifier (40), which also has been used

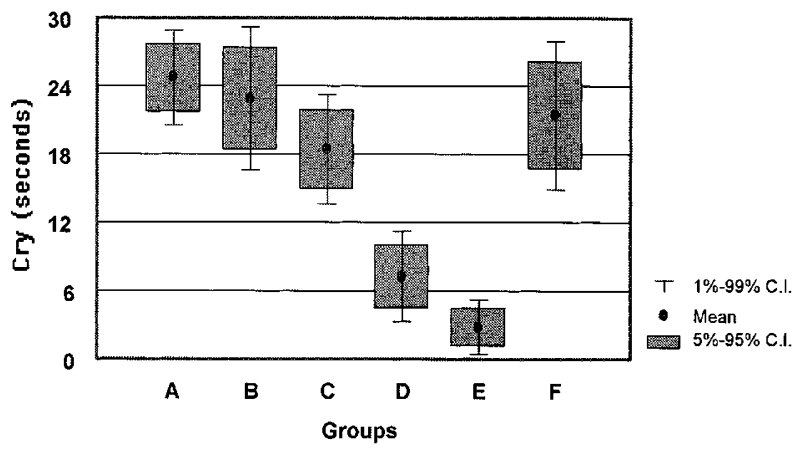

Figure 2. Cry (seconds) during the $30 \mathrm{~s}$ after the heel prick. $(A)$ controls, $(B)$ oral 33\% glucose, $(C)$ sucking, $(D)$ glucose and sucking, $(E) \mathrm{SS},(F)$ multisensorial stimulation without oral glucose. during venous blood sampling (31). Nevertheless, most of these studies were performed with a waiting time of $2 \mathrm{~min}$ between instillation of sweet solution and heel prick, sometimes too long a time for a busy ward. Moreover, analgesia limited to administration of analgesic substances leaves out human presence, which is most important in moments of pain $(41,42)$. SS includes human presence and requires only a few seconds.

Our results confirm the analgesic effect of orally administered glucose: analgesia was statistically greater in the group of babies who sucked 33\% glucose (group D) than that of babies who sucked water (group C).

When glucose was given 2 min before heel prick (B), pain score was not significantly different from control (A). Signs of pain, nevertheless, decreased when sugar was offered immediately before and during heel prick to stimulate sucking (D). This is in line with Johnston et al. (43) who advised giving sugar 2 min before and during heel prick in preterm babies for maximal analgesic effect and with those authors proposing pacifiers plus glucose during heel prick (31). Sugar, therefore, does not seem to create analgesia by a pharmacologic effect alone but seems rather to have an effect on the central control of painful stimuli (44) according to the gate control theory (45): the brain is not a passive receiver of nociceptive input but can influence the information received, deciding whether it is important enough to record. Stimulation of sensory channels prevents nociceptive nerve impulses from getting through (46, 47).

So we increased with SS the number of channels engaged during heel prick by adding auditory, tactile, visual, olfactory, and vestibular stimuli to the gustatory one. Alone (F), these stimuli did not produce an analgesic effect, or rather they increased awareness and irritated the baby (Table 2). When combined with glucose (E), however, they increased the analgesic effect. To function, they evidently require a favorable background situation such as that of a baby already intent on sucking a sweet liquid.

The preeminence of the gustatory stimulus may be explained by the fact that the chemoreceptor system is the first to become active in all species of animals and is already functional in the fetus $(48-50)$.

Different sensory stimuli have been used to activate gatecontrol mechanisms to block nociceptive transmission: massage (51) or water mattresses (52), tactile (53) and acoustic (54) stimuli or both (55), sucking (39), oral sucrose or glucose $(28,35,36,38,40,56-58)$, and other sweet liquids $(22,34)$. Nevertheless, the technique used in the present study is the first to obtain an evident and significant decrease in the response to 
pain in term neonates by stimulating various sensory channels simultaneously and in a codified manner. Simultaneous stimulation of various channels had already been used or in a noncodified manner, namely, general consolation by parents (33) or unsuccessfully combining sucrose with rocking (59).

With SS, we found an almost complete absence of pain reaction during heel prick; the babies rarely cried, and if they did, only for a few seconds (Fig. 2). Other researchers (33-37) succeeded in reducing crying of premature babies with oral sucrose, but the infants nevertheless cried for many seconds and in some cases for more than $1 \mathrm{~min}$, much more than with our technique, which reduced the mean crying time in the $30 \mathrm{~s}$ after heel prick to $2.8 \mathrm{~s}$.

Haouari et al. (37) were on the right track when they wrote, "We don't know whether simply cuddling an infant after heel prick is as effective in reducing crying as $50 \%$ sucrose." In actual fact, concentrated sugar solution is much more effective than cuddling, but the latter or at least its sensory component, i.e. massage, voice, rocking, eye fixing, adds further analgesia to the analgesic effect of glucose and provides a human factor in the form of company to a baby facing pain. SS is a technique that can be used for all newborns undergoing blood samples or other minor painful procedures.

\section{REFERENCES}

1. Anand KJ, Hickey PR 1987 Pain and its effects in the human neonate and fetus. N Engl J Med 317:1321-1326

2. Fitzgerald M, Millard C, MacIntosh N 1988 Hyperalgesia in premature infants. Lancet 1:292

3. McIntosh N 1997 Pain in the newborn, a possible new starting point. Eur J Pediatr 156:173-177

4. Menon G, Anand KJ, McIntosh N 1998 Practical approach to analgesia and sedation in the neonatal intensive care unit. Semin Perinatol 22:417-424

5. Anand KJ, Scalzo FM 2000 Can adverse neonatal experiences alter brain development and subsequent behavior? Biol Neonate 77:69-82

6. Richard T 1985 Can a fetus feel pain? BMJ 291:1220-1221

7. Beyer JE, DeGood DE, Ashley LC, Russell GA 1983 Patterns of postoperative analgesic use with adults and children following cardiac surgery. Pain 17:71-81

8. Anand KJ 1998 Clinical importance of pain and stress in preterm neonates. Biol Neonate 73:1-9

9. Stevens BJ, Johnston CC 1994 Physiological responses of premature infants to a painful stimulus. Nurs Res 43:226-231

10. Tsuji M, Saul P, du Plessis A, Eichenwald E, Sobh J, Crocker R, Volpe JJ 2000 Cerebral intravascular oxygenation correlates with mean arterial pressure in critically ill premature infants. Pediatrics 106:625-632

11. Canadian Pediatric Society. Fetus and Newborn Committee 2000 Prevention and management of pain and stress in the neonate. Pediatrics 104:454-458

12. Spaeth JP, O'Hara IB, Kurth CD 1998 Anesthesia for the micropremie. Semin Perinatol 22:390-401

13. Stevens B, Gibbins S, Franck LS 2000 Treatment of pain in the neonatal intensive care unit. Pediatr Clin North Am 47:633-640

14. Carbajal R, Simon N 1995 Sédation et analgésie chez l'enfant. Arch Pediatr 2:10891096

15. Anand KJ 2001 Consensus statement for the prevention and management of pain in the newborn. Arch Pediatr Adolesc Med 155:173-180

16. Suresh S, Anand KJ 1998 Opioid tolerance in neonates: mechanisms, diagnosis, assessment, and management. Semin Perinatol 22:425-433

17. Jacqz-Aigrain E, Burtin P 1996 Clinical pharmacokinetics of sedatives in neonates. Clin Pharmacokinet 31:423-443

18. Levene M 1995 Pain relief and sedation during neonatal intensive care. Eur J Pediatr 154:S22-S23

19. Law RMT, Halpern S, Martins RF, Reich H, Innanen V, Ohlsson A 1996 Measurement of methemoglobin after EMLA analgesia for newborn circumcision. Biol Neonate 70:213-217

20. Gourrier E, Karoubi P, El Hanache A, Merbouche S, Mouchnino G, Dhabhi S, Leraillez J 1995 Utilisation de la crème EMLA chez le nouveau-né à terme et prématuré. Etude d'efficacité et de tollerance. Arch Pediatr 2:1041-1046

21. Lemmen RJ, Semmekrot BA 1996 Muscle rigidity causing life-threatening hypercapnia following fentanyl administration in a premature infant. Eur J Pediatr 155:1067
22. Blass EM 1997 Milk-induced hypoalgesia in human newborns. Pediatrics 99:825829

23. Balon-Perin S, Kolanowski J, Berbinschi A, Franchimont P, Ketelslegers JM 1991 The effects of glucose ingestion and fasting on plasma immunoreactive betaendorphin, adrenocorticotropic hormone, and cortisol in obese subjects. J Endocrinol Invest 14:919-925

24. Tropeano G, Lucisano A, Liberale I, Barini A, Vuolo IP, Martino G, Menini E, Dell'Acqua S 1994 Insulin, C-peptide, androgens, and beta-endorphin response to oral glucose in patients with polycystic ovary syndrome. J Clin Endocrinol Metab 78:305-309

25. Blass EM, Fitzgerald E 1988 Milk-induced analgesia and comforting in 10-day-old rats: opioid mediation. Pharmacol Biochem Behav 29:9-13

26. Shide DJ, Blass EM 1989 Opioidlike effects in intraoral infusions of corn oil and polycose on stress reactions in 10-day-old rats. Behav Neurosci 103:1168-1175

27. Blass E, Fitgerald E, Kehoe P 1987 Interactions between sucrose pain and isolation distress. Pharmacol Biochem Behav 26:483-489

28. Ramenghi LA, Evans DJ, Levene MI 1999 "Sucrose analgesia": absorptive mechanism or taste perception? Arch Dis Child Fetal Neonatal Ed 80:F146-F147

29. Bellieni CV, Buonocore G, Nenci A, Franci N, Cordelli DM, Bagnoli F 2001 Sensorial saturation: an effective analgesic tool for heel-prick in preterm infants. A prospective randomized trial. Biol Neonate 80:15-18

30. Prechtl HF, Beintema DJ 1964 The neurological examination of the full term newborn infant. In: Clinics in Developmental Medicine N. 12 Heinemann Ed., London

31. Carbajal R, Chauvet X, Courdec S, Olivier-Martin M 1999 Randomized trial of analgesic effects of sucrose, glucose, and pacifiers in term neonates. BMJ 319:13971402

32. Carbajal R, Paupe A, Hoenn E, Lenclen R, Olivier-Martin M 1997 DAN: une échelle comportamentale d'évaluation de la douleur aigue du nouveau-né. Arch Pediatr $4: 623-628$

33. Overgaard C, Knudsen A 1999 Pain relieving effect of sucrose in newborns during heel prick. Biol Neonate 75:279-284

34. Bucher HU, Baumgartner R, Bucher N, Seiler M, Fauchère JC 2000 Artificial sweetener reduces nociceptive reaction in term newborn infants. Early Hum Dev 59:51-60

35. Ramenghi LA, Griffith GC, Wood CM, Levene MI 1996 Effect of non-sucrose sweet tasting solution on neonatal heel prick responses. Arch Dis Child 74:F129-F131

36. Skogsdal Y, Eriksson M, Schollin J 1997 Analgesia in newborns given oral glucose. Acta Paediatr 86:217-220

37. Haouari N, Wood C, Griffiths G, Levene M 1995 The analgesic effect of sucrose in full term infants: a randomised controlled trial. BMJ 310:1498-1500

38. Rushforth JA, Levene MI 1993 Effect of sucrose on crying in response to heel stab. Arch Dis Child 69:388-389

39. Blass EM, Hoffmeyer LB 1991 Sucrose as an analgesic for newborn infants. Pediatrics 87:215-218

40. Blass EM, Watt LB 1999 Suckling and sucrose-induced analgesia in human newborns. Pain 83:611-623

41. Als H, Duffy FH, McAnulty GB 1996 Effectiveness of individualised neurodevelopmental care in the newborn intensive care unit. Acta Paediatr 416:S21-S30

42. Als H, Gilkerson L 1997 The role of relationship-based developmentally supportive newborn intensive care in strengthening outcome of preterm infants. Semin Perinatol $21: 178-189$

43. Johnston CC, Stremler R, Horton L, Friedman A 1999 Effect of repeated doses of sucrose during heel stick procedure in preterm neonates. Biol Neonate 75:160-166

44. Lindahl S 1997 Calming minds or killing pain in newborn infants? Acta Paediatr 86:787-788

45. Melzack R, Wall PD 1965 Pain mechanisms: a new theory. Science 150:971-979

46. Wall PD 1978 The gate control theory of pain mechanism. A re-examination and re-statement. Brain 101:1-18

47. Melzack R 1999 From the gate to the neuromatrix. Pain 6:S121-S126

48. Relier JP 1996 Importance of fetal perceptions in the organization of the mother-fetus interactions. Biol Neonate 69:165-212

49. Robin M 2000 Premier regards, premiers échanges. In: Herbinet E, Busnel MC (eds) L'Aube des Sens. Stock, Paris, pp 55-64

50. Herbinet E, Busnel MC 2000 L'Aube des Sens. Stock, Paris

51. Franck LS, Lawhon G 1998 Environmental and behavioral strategies to prevent and manage neonatal pain. Semin Perinatol 22:434-443

52. Korner AF, Kraemer HC, Haffner ME, Cosper LM 1975 Effects of waterbed flotation on premature infants: a pilot study. Pediatrics 56:361-367

53. Gray L, Watt L, Blass EM 2000 Skin-to-skin contact is analgesic in healthy newborns. Pediatrics 105:e14

54. Locsin RG 1981 The effect of music on the pain of selected post-operative patients. J Adv Nurs 6:19-25

55. McIntosh N, van Veen L, Brameyer H 1994 Alleviation of the pain of heel prick in preterm infants. Arch Dis Child 70:F177-F181

56. Stevens B, Ohlsson A 2001 Sucrose for analgesia in newborn infants undergoing painful procedures (Cochrane Review). In: The Cochrane Library, Issue 4, Oxford

57. Abad F, Diaz NM, Domenech E, Robayna M, Rico J 1996 Oral sweet solution reduces pain-related behaviour in preterm infants. Acta Paediatr 85:854-858

58. Bucher HU, Moser T, Von Siebental K, Keel M, Wolf M, Duc G 1995 Sucrose reduces pain reaction to heel lancing in preterm infants: a placebo-controlled, randomized and masked study. Pediatr Res 38:332-335

59. Johnston CC, Stremler RL, Stevens BJ, Horton LJ 1997 Effectiveness of oral sucrose and simulated rocking on pain response in preterm neonates. Pain 72:193-199 